\title{
Testing the use of an analytical and mechanistic C3 -biomass accumulation model for precision fertilization
}

\author{
Mikko Hakojärvi, Mikko Hautala and Laura Alakukku \\ University of Helsinki, Department of Agricultural Sciences, P.O. Box 28, FIN-00014 University of Helsinki, Finland \\ e-mail: mikko.hakojarvi@helsinki.fi
}

\begin{abstract}
A single and uniform fertilizer application may lead to ineffective crop nutrient uptake and use. In order to enhance nutrient use efficiency the application should be adjusted according to the need of the cultivated crop. This task is challenging because weather is unknown and unpredictable over the upcoming growing season. One solution is site-specific fertilizer application in several separate events throughout the season. Such a precision fertilization method requires information on the current crop state (e.g. the availability of water and nutrients in the soil) and a crop growth model that aims to assess current crop growth and near future needs. A field experiment with varying radiation, precipitation and nutrient conditions was established to test our crop growth model performance. Spring wheat (Triticum aestivum L.) was grown using three fertilization rates with three precipitation and two radiation treatments within each fertilization treatment. The observed crop biomass accumulation in the highest fertilization treatment was considered as the highest possible in the prevailing conditions. The simulated (maximal) biomass accumulation was in agreement with the highest observed biomass yield. The results were found promising for further use of the model in crop growth evaluation during the growing season.
\end{abstract}

Key words: yield variation, water, nitrogen, biomass model, precision farming

\section{Introduction}

Cereal crops have been cultivated on $51.2 \pm 1.3 \%$ of the utilized agricultural area ( $2.3 \mathrm{M} \mathrm{ha}$ ) in Finland in years 2004-2010 (Tike 2011). During the same period the majority of cultivated cereals were spring cereals while the percentage of winter cereals was only $4.2 \pm 0.6 \%$ of total cereal production area (Tike 2011). The growing season weather varies highly during and between the seasons causing un predictable variations in crop yields that may not be related to spatial soil properties of a field (Hakojärvi et al. 2013). Since the yield level and variation in a specific field cannot be known at the moment of sowing, the optimal amount of fertilizer cannot be determined either. Thus, a more specific fertilization in a parcel scale is expected to be one of the most effective ways to control the potential soil nutrient leaching (Hyytiäinen et al. 2011, Rankinen et al. 2013). One solution to this problem may lie in a combination of split application, crop modelling and precision farming practices.

The challenge in precision farming is the variation in cultivated crop growth whether it occurs at different location on the field (spatial variation) or at different times during the growing season (temporal variation) (Pierce and Nowak 1999). Spatial variation is generally seen in fields where the growing conditions within the field vary due to e.g. spatial soil properties (Timlin et al. 2001, James and Godwin 2003, Keller et al. 2012, Hakojärvi et al. 2013) and topography (Hanna et al. 1982, Basso et al. 2009). When the growing conditions within a field vary, the crop adapts to the site-specific conditions that further leads to spatial variation in the crop growth (Wood et al. 2003, Diacono et al. 2012) and in the use and need of growth resources. In rain fed production (water for cultivated crop is provided only through precipitation) uniform applications are common e.g. in fertilizer applications (Basso et al. 2013). However, where spatial variation is present, uniform applications should be reconsidered and replaced with site-specific applications (Johnson and Raun 2003, Girma et al. 2007, Havling and Heininger 2009) that obey the crop's site-specific need. Several attempts have been made to divide the field into smaller homogenous areas, called management zones, based on site-specific soil properties (Fleming et al. 2000, Fridgen et al. 2004, Shanahan et al. 2008) or yield maps from previous years (Blackmore et al. 2003, Welsh et al. 2003a, b, Basso et al. 2013). Furthermore, the management zones have been the basis for several suggested site-specific crop management strategies (Basso et al. 2001, Batchelor et al. 2002, Blackmore et al. 2003, Godwin et al. 2003, Welsh et al. 2003a, b, Shanahan et al. 2008, Basso et al. 2011).

Despite all the efforts to consider or counteract spatial yield variation, the results have not been straightforward as Pierce and Nowak (1999) hypothesized in their early study. Temporal variation has been found to cause unstable spatial patterns in the observed yields (Blackmore et al. 2003, Wood et al. 2003, Basso et al. 2009, Basso et al. 2013). Suggested site-specific action effects have been negligible or present only during limited years due to the 
temporal variations (Basso et al. 2013, Basso et al. 2012, Godwin et al. 2003). Especially, the combined effect of amount and timing of the precipitation (Taylor et al. 2003, Basso et al. 2012, Sadras et al. 2012, Basso et al. 2013) together with soil water holding capacity (Asseng et al. 2001, Basso et al. 2012, Basso et al. 2013, Hakojärvi et al. 2013) have been emphasized in the context of rain fed production.

The important role of water on crop growth has been seen in fertilizer management studies where the effect of nitrogen fertilizer on crop growth has been found to decrease with decreasing amount of crop available water (e.g. Angus and Fisher 1991, Esala 1991, Peltonen 1995, Olesen et al. 2000, Petersen 2004, Pedersen and Jørgensen 2007, Basso et al. 2012). The crop water availability is dependent on the field's site-specific water retention properties (Asseng et al. 2001, Timlin et al. 2001, Hakojärvi et al. 2013) and the current growing season precipitation (Taylor et al. 2003, Sadras et al. 2012, Basso et al. 2013). Lack of water ultimately limits the highest attainable yields in rain fed production and varies in both space and time (Asseng et al. 2001, Basso et al. 2012). The nitrogen should be applied in respect to the water limited yield potential in order to make the crop cultivation economically and environmentally efficient and sustainable (Mulla et al. 1992, Hancock et al. 2011, Basso et al. 2012).

One suggested solution, generally used with winter grains, is split application where the nutrients for the cultivated crop are provided in two or more fertilizer applications during the growth (Hakojärvi and Hautala 2010, Basso et al. 2011). When applying the nutrients this way, the synchrony between nitrogen availability and crop nitrogen demand (Jørgensen and Jørgensen 2007, Shanahan et al. 2008, Hancock et al. 2011) can be enhanced and the threat of water soluble nutrients leaching to water systems can be decreased (|ørgensen and Jørgensen 2007, Barberi et al. 2008, Singh et al. 2008, Basso et al. 2011, Walsh et al. 2013). M any studies have used split applications with predefined application rates (Esala 1991, Peltonen 1995, Olesen et al. 2000, Asseng et al. 2001, Kuisma 2002, Singh et al. 2008, Basso et al. 2009, Basso et al. 2011, Hancock et al. 2011, Basso et al. 2012) but observing the current growth conditions in defining the second application rate has also been suggested (Asseng et al. 2001, Hakojärvi and Hautala 2010, Basso et al. 2011, Basso et al. 2012, Walsh et al. 2013). In these studies the current nitrogen status of the crop has been found to be an important measure but the information on crop water or stress status has also been found to be necessary for a successful nutrient prescription (Angus and Fischer 1991, Timlin et al. 2001, Fitzgerald et al. 2006, Jorgensen and Jorgensen 2007, Basso et al. 2013, Walsh et al. 2013).

In addition to the field experiments, many have studied the yield variation with crop models (Sadler et al. 2000, Batchelor et al. 2002, Basso et al. 2011). Due to their long-term development the most advanced crop models describe the growth and the phenomenon in a crop in a very detailed manner (Bouman et al. 1996, Van Ittersum et al. 2003). Therefore the advanced crop models provide a versatile and important research tool for the studies on understanding the crop behaviour and responses to changes in growing conditions under e.g. the climate change or different cultivation practices. However, there are two major problems in using the crop models on a farm scale. Firstly, the models do not sufficiently consider spatial processes (Sadler et al. 2000). Secondly, the availability of spatial information about the field properties (especially soil) is limited (Sadler et al. 2000, Batchelor et al. 2002). The spatial information on field properties is inevitably needed for the model parameter values (Sadler et al. 2000, Batchelor et al. 2002) but the choice of model will affect the amount of information needed. For example, process-oriented models have been successfully used together with measured spatial soil properties and initial soil moisture (Basso et al. 2001, Batchelor et al. 2002).

In this study we approached the problem by simulating the potential biomass accumulation of spring wheat (Triticum aestivum $L$.) in conditions corresponding an extensively managed field. The potential biomass yield in this study is equivalent to biomass yield in conditions where weeds, diseases and pests are effectively controlled and water or nutrients are not limiting the growth. Furthermore, the simulated potential biomass yield should be very close to the biomass yield in actual farming when the temperature is optimal and precipitation is sufficient during the growing season. We simulate the potential biomass accumulation with a process based and mechanistic crop growth model (Hautala and Hakojärvi 2011) that was developed to describe the maximal biomass accumulation in prevailing growing conditions. The model has as few parameters as possible, which has been found to be beneficial in modelling studies (Boote et al. 1996, Sinclair and Seligman 1996, Brooks et al. 2001, Lark 2001) and further should be advantageous for spatial data sufficiency (model parameter values) and for practical farming applications (Adams et al. 2000, M orison et al. 2008). A field experiment with different radiation and fertilizer treatments was established in order to study the effect of radiation and nutrients on the crop growth and to gain data to test the model. The objective of the study was to test the model in varying radiation and nitrogen conditions. The outcome of the comparison between simulated and observed biomass and leaf area values are discussed in the context of divided fertilizer application in real farm situation. 


\section{Materials and methods \\ C3 crop growth model}

The analytical crop growth model (Hautala and Hakojärvi 2011) with parameter values from Table 1 (essentially the same as in Hautala and Hakojärvi (2011)) and measured radiation (I) and precipitation as inputs was used to simulate the total biomass (BM) accumulation during the experiment period. The crop growth model simulates the highest attainable (maximum) biomass yield in prevailing moisture and radiation conditions. The model contains no free parameters that could have arbitrary values (for fitting purposes) because all parameters of the model are based on physics, chemistry or crop physiology. Therefore the most parameters in Table 1 were measured in actual field conditions or were taken from literature.

Table 1. Crop model parameters used in the simulations. Unless cited, the values were calculated from the data collected from the field experiment carried described below.

\begin{tabular}{|c|c|c|c|}
\hline Parameter & Abbreviation & Value & Unit \\
\hline \multicolumn{4}{|l|}{ Radiation- and leaf-area-limited crop growth } \\
\hline Radiation use efficiency ${ }^{1}$ & RUE & $2.8 \times 10^{-9}$ & $\mathrm{~kg} \mathrm{~J}^{-1}$ \\
\hline Maximum PAR for leaf ${ }^{2}$ & $\mathrm{I}_{\text {sat }}$ & 100 & $W m^{-2}$ \\
\hline Seedling density & SD & 537 & plants $\mathrm{m}^{-2}$ \\
\hline Specific leaf area & SLA & 30.7 & $\mathrm{~m}^{2} \mathrm{~kg}^{-1}$ \\
\hline Mass of the seedling & $m_{s}$ & 32.9 & $\mathrm{mg}$ \\
\hline Leaf weight ratio & LWR & 0.26 & \\
\hline \multicolumn{4}{|l|}{ Water-limited crop growth } \\
\hline Water use efficiency & WUE & 0.0081 & $g_{\mathrm{CO} 2} g_{\mathrm{H} 2 \mathrm{O}}^{-1}$ \\
\hline Field capacity, $\Psi=-10 \mathrm{kPa}$ & FC & 0.38 & $m^{3} m^{-3}$ \\
\hline Permanent wilting point, $\Psi=-1500 \mathrm{kPa}$ & PWP & 0.11 & $m^{3} m^{-3}$ \\
\hline Daily root growth & $r_{\text {growth }}$ & 0.01 & $\mathrm{~m} \mathrm{~d}^{-1}$ \\
\hline Maximum rooting depth & $r_{\max }$ & 0.7 & $\mathrm{~m}$ \\
\hline
\end{tabular}

${ }^{1}$ M onteith and M oss (1977), 2)Hautala and Hakojärvi (2011).

As a function of time (t), the growth is divided into two phases: the exponential and the linear phase. At an early stage of the growth, the biomass accumulation is exponential due to the small leaf area index (LAl, $\mathrm{m}^{2}$ leaf $\mathrm{m}^{-2}$ area-1) $^{-1}$ of the crop:

$$
\left\{\begin{array}{l}
\mathrm{BM}(\mathrm{t})=\mathrm{BM}(0) \cdot \mathrm{e}^{\mathrm{K} \cdot \mathrm{t}}=\mathrm{m}_{\mathrm{s}} \cdot \mathrm{SD} \cdot \mathrm{e}^{\mathrm{K} \cdot \mathrm{t}}, \\
\text { when } L A \mathrm{I}<\frac{\mathrm{I}(\mathrm{t})}{\mathrm{I}_{\text {sat }}} \text { andt }<\mathrm{t}_{0} \\
\mathrm{t}_{0}=\ln \left(\frac{\mathrm{I}\left(\mathrm{I}_{\mathrm{sat}}\right.}{\mathrm{BM}(0) \cdot \mathrm{SLA} \cdot \mathrm{LWR}}\right) \cdot \frac{1}{\mathrm{~K}}, \mathrm{~K}=\mathrm{RUE} \cdot \mathrm{I}_{\mathrm{sat}} \cdot \mathrm{LWR} \cdot \mathrm{SLA} .
\end{array}\right.
$$

The four most important parameters at the exponential stage are the ones which have an effect on radiation interception and leaf area expansion (Table 1). These parameters are leaf weight ratio (LWR), specific leaf area (SLA), radiation use efficiency (RUE) and highest utilizable radiation for leaf $\left(I_{\text {sat }}\right)$. The actual leaf area of the crop is determined by the LWR which defines the biomass distribution between leaves (i.e. biomass in leaves divided by total biomass of the crop) and biomass but also by the SLA which is the leaf area divided by leaf dry mass. The usage of radiation with existing leaf area is limited by RUE and $I_{\text {sat }}$, which define the efficiency of using intercepted radiation into photosynthesis and the maximum radiation intensity that a leaf is capable of intercepting, respectively. In addition, the prevailing biomass can be calculated according to measured leaf area of the crop but only during the exponential growth (Equation 2). 


$$
\mathrm{BM}(\mathrm{t})=\frac{\mathrm{LAI}}{\mathrm{SLA} \cdot \mathrm{LWR}}
$$

When the leaf area has expanded large enough to utilize all incoming radiation the growth becomes linear and independent on changes in the leaf area:

$$
\left\{\begin{array}{l}
B M(t)=B M\left(t_{0}\right)+R U E \cdot I\left(t-t_{0}\right), \\
\text { when } L A I \geq \frac{I(t)}{I_{\text {sat }}} \text { and } \geq t_{0} .
\end{array}\right.
$$

Therefore the crop growth during the linear growth depends only on the parameter RUE. Together with the measured I $(t)$ RUE determines the daily crop growth. The time interval $(\Delta t)$ was in the measurements and in the simulations 0.5 hours.

Eqs. 1 and 3 give the radiation limited crop growth. The amount of water available for crop growth is calculated from crop root growth, soil properties and rainfall (Hautala and Hakojärvi 2011). Initially the soil moisture content is assumed to be at field capacity (FC). In the model the roots are assumed to grow at certain rate $\left(r_{\text {growth }}\right)$ until they reach the maximum depth $\left(r_{\text {max }}\right)$. The water in soil within the rooting depth is available for the crop between $\mathrm{FC}$ and permanent wilting point (PWP). Precipitation at the weather station close to the experiment location (350 meters) was used as input for water limited growth. This calculation for crop water availability is the simplest form of calculation and has its limitations. In case of e.g. layered soil structure the crop model can be used with more appropriate calculation routine (Hakojärvi et al. 2013). The values of other parameters used for calculating the water limited growth are presented in Table 1. The beginning of the simulation was set to correspond the time of observed emergence of the seedlings ( $148^{\text {th }}$ day of year, later DOY). As the model is capable of simulating only the vegetative growth phase the end of the simulation was set according to the leaf senescence. The beginning of the leaf senescence was found to be $205^{\text {th }}$ DOY and at $217^{\text {th }}$ DOY the crop reached the yellow ripening when there were no photosynthesis capable leaves present.

The parameter values $m_{\mathrm{s}^{\prime}}$ SLA and SD (Table 1) were calculated from data collected from the field experiment introduced in the section 2.2. The measured values for specific leaf area (SLA) during the experiment varied from 28 to $32 \mathrm{~m}^{2} \mathrm{~kg}^{-1}$ and the lowest value was obtained from the site without fertilization. The mean of the measured SLA values was calculated and used in the simulations (Table 1). It is to be stressed that the model has no adjustable parameters; it does not contain any calibration or validation but the parameter values must represent the studied conditions.

\section{Field experiment for testing of model}

A field experiment was established in Helsinki, Finland $\left(60^{\circ} 13^{\prime} 19.357^{\prime \prime} \mathrm{N}, 25^{\circ} 0^{\prime} 36.881^{\prime \prime} \mathrm{E}\right)$ on a clay soil classified as Sulfic Cryaquept (M okma et al. 2000). The test field had a high ground water level and should thus be ideal to obtain maximum biomass in prevailing radiation conditions. Acknowledging the need for replicates in traditional field trials the purpose of the field experiment in this study was to obtain information about the crop growth in various radiation and precipitation conditions for testing the model. Therefore the replicates are not necessary and in case of replicated trial the model parameter values should be measured separately from each replicate instead of using averaged values. The performed test is similar to testing a physical model where the outcome is that the model either describes the phenomenon correctly or not. It is acknowledged that there may be variation in the growth because the crop is able to regulate the growth within certain limits. However, the processes involved in the crop growth are ultimately limited by laws of the physics that the crop cannot significantly exceed.

Before spring sowing, the soluble nitrogen $(\mathrm{N})$ content of top soil $(0-0.2 \mathrm{~m})$ was analysed in a laboratory. The soil samples were extracted with $0.1 \mathrm{M}$ potassium sulphate solution and analysed with Kjeldahl method using Devarda's alloy as a catalyst (Viljavuuspalvelu 2010). Soluble nitrogen content was $28.0 \pm 1.9 \mathrm{~kg} \mathrm{ha}^{-1}$ in the layer of 0-0.2 m. Spring wheat (Triticum aestivum L., Amaretto) was sown (Fig. 1) on $20^{\text {th }}$ May 2010 (140 th DOY). The observed emergence was $537 \pm 5$ seedlings per square meter. The row spacing was $125 \mathrm{~mm}$ and the fertilization was placed between every second crop row (fertilizer row spacing $250 \mathrm{~mm}$ ). Three plots were given three different fertilizer rates at the time of sowing in order to create four different $\mathrm{N}$ treatments according to Figure 1. N-P$\mathrm{K}$ fertilizer (28-3-5) was used in the application and $\mathrm{N}$ rates for the three treatments were 15,50 and $150 \mathrm{~kg} \mathrm{ha}^{-1}$. 

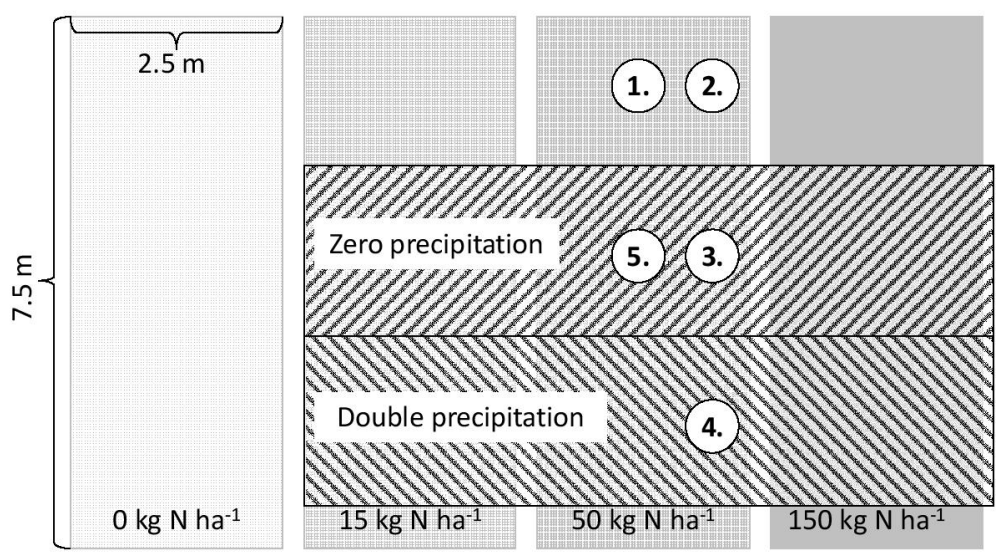

Fig. 1. The experimental setup with four fertilization treatments $(0,15,50$ and 150 $\mathrm{kg} \mathrm{N} \mathrm{ha-1}$ ). A shelter was used to create the radiation treatment and to cover the dry zone from the precipitation and to increase precipitation on the wet zone. Numbered circles are the locations of permanently installed measurement devices presented in Table 2.

All fertilized plots were exposed to three different amounts of precipitation $(0,1$ and 2 times the natural precipitation). To achieve three different precipitation rates (Fig. 1), the zero and double precipitation treatments were covered with a plastic shelter installed at 0.9-1.0 m height (Fig. 2). The shelter transferred the precipitation from zero precipitation zone to double precipitation zone (Fig. 1). Even though the shelter material was transparent, it decreased the amount of radiation in the zero and double precipitation treatments (Fig. 1). The zones without shelter received the natural amount of precipitation and solar radiation.

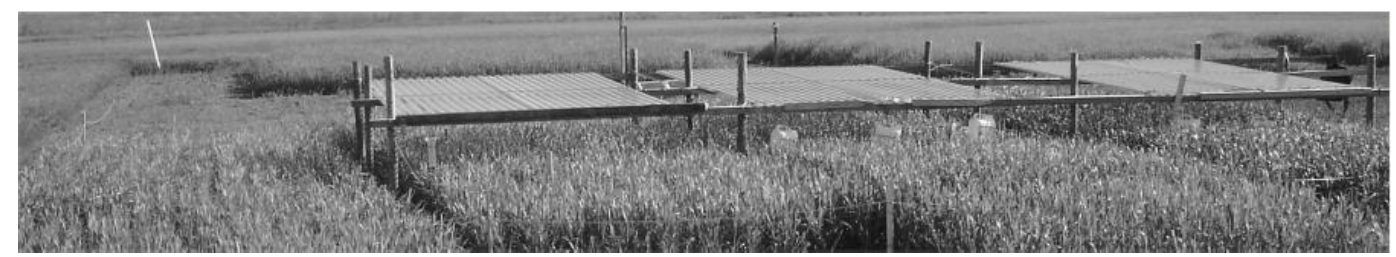

Fig. 2. The field experiment setup and the structure of the shelter.

\section{Crop growth conditions during the growing season}

In southern Finland, the growing season 2010 was very dry and rather warm in comparison with the long-term average (Fig. 3). In the experiment year, the precipitation during the most intensive growth (June and July) was clearly lower than the long-term average of the years 1970-2000 (Fig. 3). In M ay 2010, the precipitation was, however, $30 \mathrm{~mm}$ greater than the long-term average which delayed the spring wheat sowing. The temperature in $M$ ay was notably lower than the long-term mean temperature. Despite the cold and wet beginning of the growing season, the high temperatures favoured the growth rate in July and August.

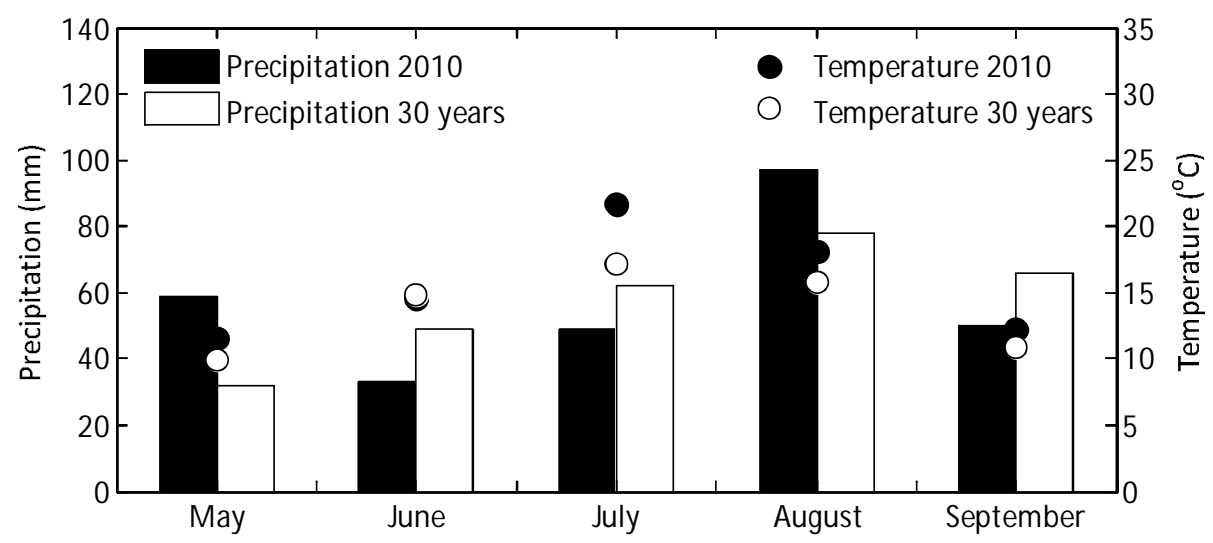

Fig. 3. M onthly precipitation and mean temperature statistics from the nearest official weather station (Kaisaniemi, about $10 \mathrm{~km}$ from our experiment site) (Finnish M eteorological Institute 2010) and longterm average values (1971-2000) from the same station (Drebs et al. 2002). 


\section{Field and laboratory measurements}

A wide range of measurements were performed in the experiment during the growing season 2010 to determine the soil and weather conditions, and crop development (Fig. 1 and Table 2). The sensors for continuously measuring soil and canopy related parameters were installed in the zone of natural precipitation (location 1, Fig. 1). This location was used as a reference point for the altered growing conditions below the shelter. In other treatment zones, the differences in growth conditions were in the amount of the fertilizer, precipitation and radiation since the soil type and structure were found homogenous within the experiment area. The devices marked with asterisk (Table 2) were used regularly once a week in order to gain supporting information about the quantities which were measured continuously. The roots were observed on a weekly basis from a hole dug to the left edge of the $0 \mathrm{~kg} \mathrm{~N} \mathrm{ha}^{-1}$ treatment (Fig. 1) and the depth of the roots was measured. In addition, the ground water level was measured from two narrow, $1 \mathrm{~m}$ deep holes at two corners (the upper left and lower right) of the experiment on a weekly basis.

Table 2. Devices and sensors used at the experiment and their range and resolution reported by the manufacturer. The locations of stationary sensors are presented in Figure 1. The ones used on a weekly basis are marked with asterisk.

\begin{tabular}{|c|c|c|c|c|c|}
\hline Location & Device & Description & Range & Resolution & Unit \\
\hline 1 & 1)M P406 & Soil volumetric water content & $0 . . .100$ & - & $\%$ \\
\hline \multirow[t]{2}{*}{1} & 2)Decagon M PS-1 & Soil water potential & $-10 \ldots-500$ & 1 & kPA $(-10 \ldots-100 \mathrm{kPa})$ \\
\hline & & & & 4 & kPA $(-100 \ldots-500 \mathrm{kPa})$ \\
\hline 1 & 3)Decagon QSO-S & Photosynthetically active radiation & $0 \ldots 5000$ & 2 & $\mu \mathrm{mol} \mathrm{m} \mathrm{m}^{-2} \mathrm{~s}^{-1}$ \\
\hline 1 & 4) HIH-4000-001 & Air relative humidity & $0 \ldots 100$ & - & $\%$ \\
\hline 1 & ${ }^{5)}$ Calex EL101LTO & IR radiation (of the canopy) & $-20 \ldots 100$ & - & ${ }^{\circ} \mathrm{C}$ \\
\hline \multirow[t]{2}{*}{$2,3,4$} & ${ }^{6)} M$ iniTrase (TDR)* & Soil volumetric water content & $0 \ldots 100$ & - & $\%$ (full scale) \\
\hline & 7)Decagon LP-80* & PAR/LAI ceptometer & $0 \ldots 2500$ & 1 & $\mu \mathrm{mol} \mathrm{m} \mathrm{m}^{-2} \mathrm{~s}^{-1}$ \\
\hline \multirow[t]{2}{*}{1,5} & 8)TinyTag TGU-4500 & Canopy air relative humidity & $0 \ldots 95$ & 0.3 & $\%$ \\
\hline & & Canopy air temperature & $-20 \ldots 85$ & 0.01 & ${ }^{\circ} \mathrm{C}$ \\
\hline
\end{tabular}

${ }^{1)}$ ICT International 2011, ${ }^{2)}$ Decagon Devices Inc. 2009a, ${ }^{3)}$ Decagon Devices Inc. 2009b, ${ }^{4) H o n e y w e l l ~ I n t e r n a t i o n a l ~ I n c . ~ 2005, ~ 5) C a l e x ~}$

Electronics Limited 2005, 6)Soil M oisture Equipment Corp. 2011, 7)Decagon Devices Inc. 2010, 8)Tinytag 2011.

The crop growth was determined from each treatment zone with biomass samples taken at DOYs 148, 152, 162, 165 and 204. Small samples ( $0.2 \mathrm{~m}$ of crop row, 13 plants) were taken because the experiment area was limited and growing conditions within the treatments were to be unchanged in terms of crop density. In the first two samples (DOYs 148 and 154) the roots were included in the sample and they were extracted from soil by washing to avoid the loss of roots. After the $154^{\text {th }}$ DOY the roots had grown too large to be precisely extracted from soil and they were excluded from the samples. At this time, the portion of biomass located in the roots was observed to be $30 \%$ of the total biomass of the crop, which was in agreement with an earlier study (Poorter and Nagel 2000). Thereafter this root mass fraction was used in the total crop biomass calculation. The simulation output is the total biomass including all crop parts. Therefore this quantity is used throughout this paper. The samples were oven dried $\left(105^{\circ} \mathrm{C}, 24 \mathrm{~h}\right)$ and weighed. The average crop values were used to calculate the total biomass (dry matter including the roots) with the same seedling density as was used in the simulations. Before oven drying and weighing, the leaf area of individual plants in the biomass samples was measured for determination of SLA.

The leaf growth was measured with Decagon LP-80 which measures the light interception in canopy and calculates the LAI (Decagon Devices Inc. 2010). This measurement was performed on a weekly basis. The leaf area growth was calculated also from continuous radiation measurements. Time period of eight hours, four hours before noon and four hours after noon, was used in the calculation of average radiation above and below the canopy. The difference between these values is the radiation intercepted by the canopy. LAI was calculated by dividing the intercepted radiation by the maximal absorption capacity of leaf $\left(100 \mathrm{~W} \mathrm{~m}^{-2}\right)$.

From the experiment field areas of $1.5 \mathrm{~m}^{2}(1 \mathrm{~m} \times 1.5 \mathrm{~m})$ were harvested 85 days after sowing ( $225^{\text {th }}$ DOY). Every area was harvested in six equally sized subplots $(0.25 \mathrm{~m} \times 1 \mathrm{~m})$ in order to ensure that there were no changes in a smaller scale than the experiment setup would create, i.e. variations inside a single treatment. During the harvest, the number of plants was counted to get a value for parameter SD. The crop above the soil surface was cut from each subplot and was collected into sheaves, which were treated separately. The dry matter yield of straw and grain were determined from each subplot. After the separate analyses of six subplot harvests from each area the final results for each zone were calculated. 
The difference between the observed $\left(\mathrm{Y}_{\mathrm{i}, \text { bbs }}\right)$ and simulated $\left(\mathrm{Y}_{\mathrm{i}, \mathrm{sim}}\right)$ results was compared with root mean square (RM SE) value (Equation 4). The RM SE values were calculated for biomass and leaf area separately for each treatment in the experiment. The smaller the RM SE value was the closer the simulated values were to the observed ones.

$$
R M S E=\sqrt{\frac{\sum_{i=1}^{n}\left(Y_{i, 0 b s}-Y_{i, s i m}\right)^{2}}{n}}
$$

\section{Results}

\section{Soil moisture in the natural precipitation treatment during the growing season}

The aim was to evaluate the model in optimal soil moisture conditions. This was confirmed by measuring the soil water content and soil water potential, root growth, ground water level and the canopy temperature. Water availability for the crop growth was confirmed by measuring the air temperature in the canopy and canopy temperature via infrared radiation (Table 2) during the growing season (Fig. 4). During the vegetative period the temperature of the canopy was lower than the temperature of the air because the transpiration of water during photosynthesis decreased the canopy temperature.

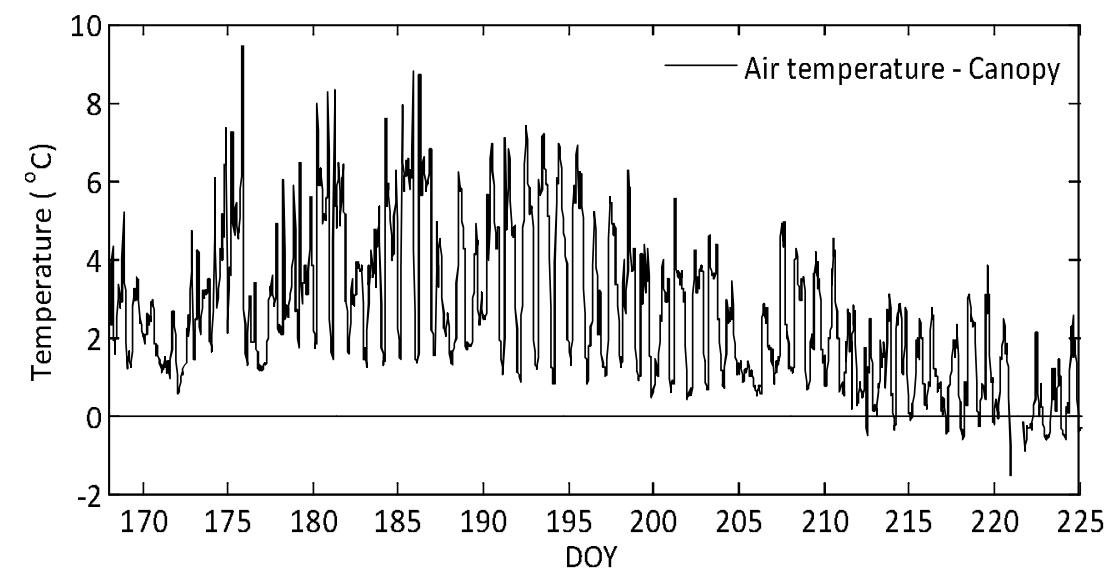

Fig. 4.The difference between air temperature in the canopy and canopy temperature at the location 1 of the experiment field (Fig. 1). In order to clarify the temperature difference the result in the graph is median filtered (over three hours, six consecutive results).

Figure 5 presents the results of continuous volumetric soil water content and soil water potential measurements from the zone of natural precipitation and $50 \mathrm{~kg} \mathrm{~N}^{-1}$ fertilization. In the beginning of the growing season, precipitation had clear impact on the sensors in the $0-0.2 \mathrm{~m}$ topsoil layer indicating that the clay soil was moist and able to conduct the water from soil surface deeper into the soil (Fig. 5). Later showers increased soil moisture content only in the 0-0.05 m surface layer.

According to the measured soil water content, the top of the soil $(0$ to $0.05 \mathrm{~m})$ had dried due to the evaporation (before $161^{\text {st }}$ DOY, Fig. 5A). The soil moisture content at the top of the soil changed rapidly at the time of rainfall events $\left(162^{\text {nd }}\right.$ and $170^{\text {th }}$ DOY's, Fig. $\left.5 A\right)$. Deeper in the soil, the main part of soil drying was due to the crop water uptake (transpiration). The rate of drying increased when the roots reached the sensor depth (Fig. 5B).

The soil water potential sensor Decagon M PS-1 should be able to determine soil water potential until -500 kPa suction (Decagon Devices Inc. Pullman, WA, USA). However, values close to the sensor limit or furthermore close to PWP were not observed. The soil water potential measurements as well as the weekly observed rooting depth (data not shown) and the measured canopy temperature (Fig. 4) indicated that soil water conditions did not limit the crop growth. Although the soil water potential at the $0.4 \mathrm{~m}$ depth reached low values by the $190^{\text {th }} \mathrm{DOY}$, the roots continued growing into deeper soil layers, reaching $0.56 \mathrm{~m}$ depth by the $197^{\text {th }}$ DOY. These observations revealed that the tips of fresh, living roots were always found in the moist soil indicating continuously available water for crop growth. 
A)

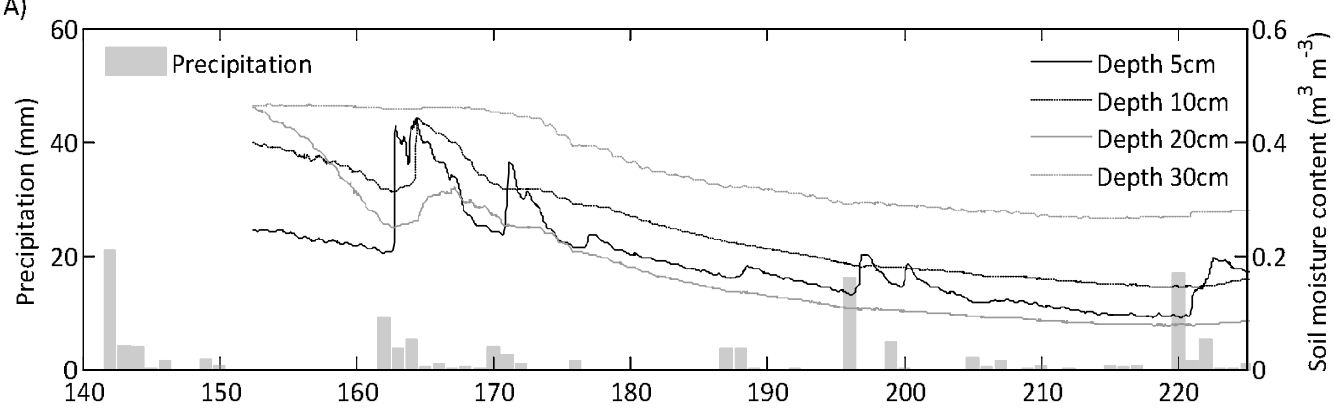

B)

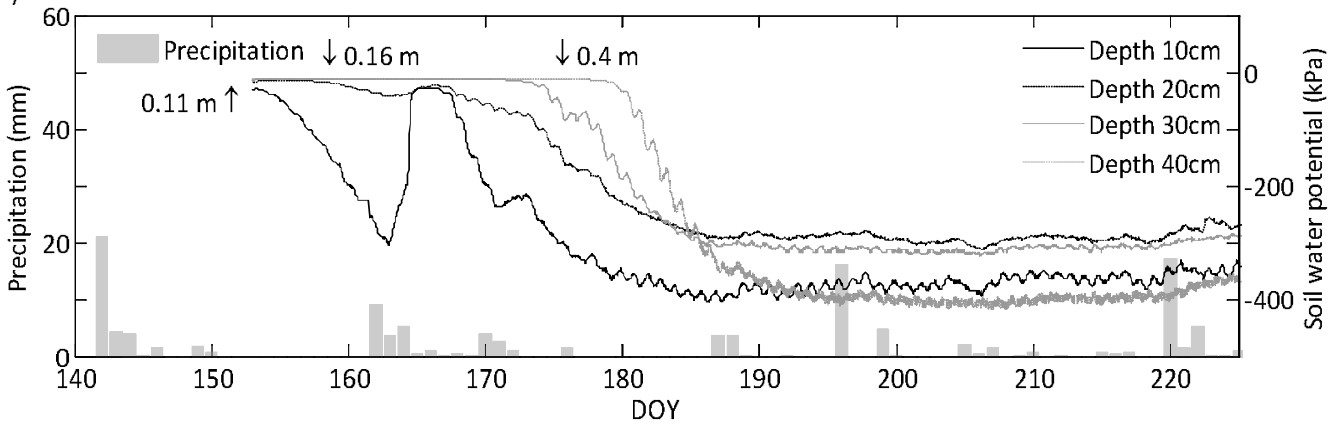

Fig. 5. Daily precipitation (Vaisala WXT510), soil volumetric water content ((A) ICT International MP 406) at 0.05, $0.1,0.2$ and $0.3 \mathrm{~m}$ depths and soil water potential ((B) Decagon M PS-1) at $0.1,0.2,0.3$ and $0.4 \mathrm{~m}$ depths as a function of time at the location 1 (Fig. 1) during the growing season 2010. The arrows in Figure B are the measured depths of the roots (in meters, from the top of the soil) from representative days.

In addition to the rooting depth determinations the ground water level was observed once a week. The ground water level never decreased below $0.85 \mathrm{~m}$ and during the root observations the soil was visually observed to be moist $0.3 \mathrm{~m}$ above the ground water level. Therefore the crop had available water in the subsoil all the time.

\section{Simulated and observed dry biomass accumulation}

All the zones of zero and double precipitation were covered with a shelter (Fig. 2) and thus obtained less radiation than the zone of natural precipitation. The influence of the shelter material on radiation was determined in the experiment location at the time of sowing in M ay over a six-day period. The measurement was conducted after shelter installation by measuring the PAR above the shelter and PAR at the ground level between the seed rows. The transmittance of the shelter was $79.0 \pm 0.5 \%$ of PAR. This value was used in simulating the growth of the crop below the shelter. The air temperature difference between the canopies below and outside the shelter was $1{ }^{\circ} \mathrm{C}$.

The biomass accumulation in the beginning of the growth was equal in all simulated precipitation treatments (data not shown). The simulated biomass accumulation during the linear phase of the growth has been fluctuating (Fig. 6) which is due to the observed changes in the PAR intensity. The end of simulation was set to be at $207^{\text {th }}$ DOY to compensate the leaf scenesense between the DOYs 205 and 217 and it appeared in Fig. 6 as a sharp corner at the end of all the simulated total biomass curves.

According to the simulated total biomass accumulations, the treatments with no precipitation during the growing season suffered from a small shortage of water from the $198^{\text {th }}$ DOY onwards (data not shown) that led to the lowest simulated total biomass yield (Table 3). In the field experiment the yield in no precipitation and double precipitation treatments was almost the same and the effect of a drought was not distinct (Table 3). Also all the other measurements (soil water potential, root measurements and the leaves temperature in the crop canopy) indicated enough water for the crop growth. Overall the effect of the three different precipitations had lower effect on the simulated biomass accumulation than the reduced radiation (Table 3). 


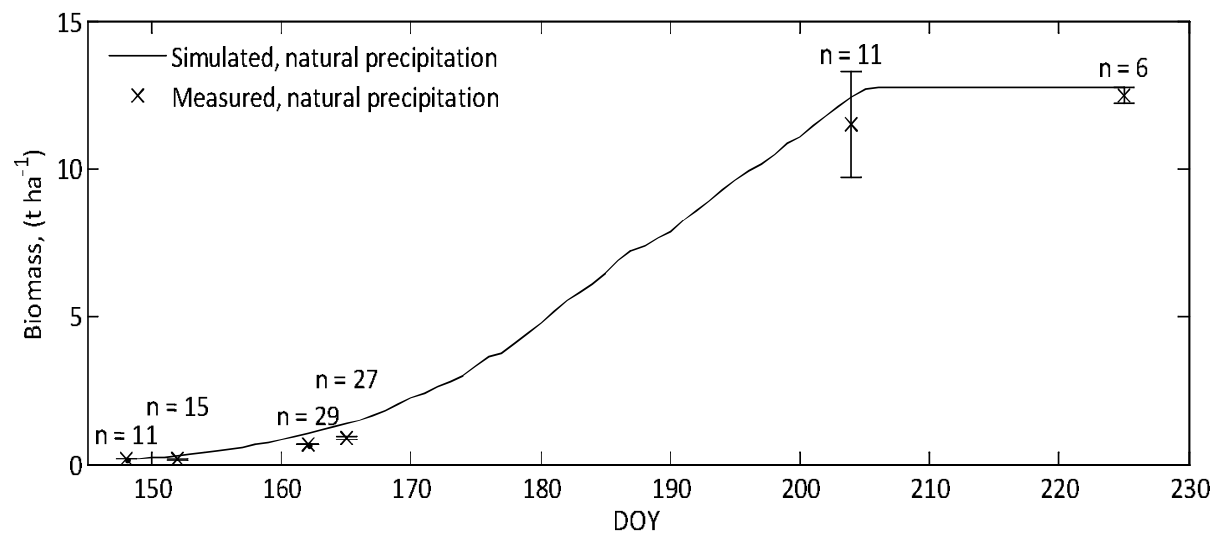

Fig. 6. Simulated crop total biomass accumulation (dry matter) for the natural precipitation treatment with $150 \mathrm{~kg} \mathrm{~N} \mathrm{ha}^{-1}$ fertilization. The error bars in the observed biomasses describes the standard error of the mean and the number of samples ( $\mathrm{n}$ ) used in the calculation is present above each result.

The observed biomass yields of the various treatments in the experiment are presented in Table 3 together with simulated biomass yields. The shelter affected the biomass accumulation in the zero and double precipitation treatments which together form the radiation treatment. The decrease in the biomass yield of radiation treatments (Table 3) was on average $78.7 \pm 2.0 \%$ and the decrease in radiation due to the shelter was $79.0 \pm 0.5 \%$.

The effect of nitrogen fertilization was noticeable through the experiment (Table 3). The biomass yield compared to the unfertilized treatment $\left(8100 \pm 500 \mathrm{~kg} \mathrm{ha}^{-1}\right)$, increased by 17,52 and $54 \%$ for the fertilizer treatments 15,50 and $150 \mathrm{~kg} \mathrm{~N} \mathrm{ha}{ }^{-1}$, respectively. Although the highest fertilization treatment produced the highest yield the difference between 50 and $150 \mathrm{~kg} \mathrm{~N} \mathrm{a}^{-1}$ treatments in the natural precipitation zone was negligible (Table 3). The biomass yield decreased as the amount of fertilizer was decreased (Table 3).

Table 3. Observed and simulated total biomass yields (dry matter, including the roots) and observed harvest index. Standard error $(n=6)$ and harvest index (grain yield divided by the biomass above ground) were also calculated for the different treatment zones (Fig. 1).

\begin{tabular}{|c|c|c|c|c|c|}
\hline \multicolumn{6}{|c|}{ Nitrogen treatment, $\left(\mathrm{kg} \mathrm{ha}^{-1}\right)$} \\
\hline & 15 & 50 & 150 & Simulated & \\
\hline \multirow[t]{2}{*}{ Normal precipitation } & $9530 \pm 120$ & $12300 \pm 100$ & $12500 \pm 300$ & 12800 & Dry biomass yield $\left(\mathrm{kg} \mathrm{ha}^{-1}\right)$ \\
\hline & 0.48 & 0.48 & 0.48 & & Harvest Index \\
\hline \multirow[t]{2}{*}{ No precipitation } & $7400 \pm 400$ & $8900 \pm 200$ & $10500 \pm 400$ & 9800 & Dry biomass yield $\left(\mathrm{kg} \mathrm{ha}^{-1}\right)$ \\
\hline & 0.48 & 0.46 & 0.48 & & Harvest Index \\
\hline \multirow[t]{2}{*}{ Double precipitation } & $7900 \pm 400$ & $9220 \pm 150$ & $10100 \pm 600$ & 10500 & Dry biomass yield $\left(\mathrm{kg} \mathrm{ha}^{-1}\right)$ \\
\hline & 0.48 & 0.45 & 0.4 & & Harvest Index \\
\hline
\end{tabular}

The model performance was evaluated by calculating the root mean square error (RM SE, Equation 4) between the observed and simulated biomass values (Table 4). In the model the PAR and water availability can limit the biomass accumulation but otherwise the growing conditions are assumed to be optimal. Therefore the difference between the simulated and observed biomass yield indicates a lack in some of the other growth resources. In the RM SE values were the lowest for the highest fertilization treatment (Table 4). In the case of double precipitation the $50 \mathrm{~kg} \mathrm{~N} \mathrm{ha}^{-1}$ treatment had the lowest RM SE (Table 4).

Table 4. The root mean square errors (RMSE) between the simulated and observed biomasses $(n=6)$.

Natural precipitation

Zero precipitation

Double precipitation

\begin{tabular}{cccc} 
N 15 kg ha-1 & N 50 kg ha-1 & N 150 kg ha-1 & \\
\cline { 1 - 3 } 1500 & 970 & 560 & $\mathrm{~kg} \mathrm{ha}^{-1}$ \\
1300 & 490 & 360 & $\mathrm{~kg} \mathrm{ha}^{-1}$ \\
1700 & 1100 & 1700 & $\mathrm{~kg} \mathrm{ha}^{-1}$
\end{tabular}




\section{PAR and LAI}

At the beginning, the crop growth is limited by small leaf area which is not large enough to capture all the incoming radiation. Once the leaf area of the crop has expanded enough to capture all the incoming radiation the differences in the radiation treatments become visible in the simulated crop leaf areas (165 $5^{\text {th }}$ DOY, Fig. 7) as well as in the simulated biomasses (Fig. 6). The simulated leaf area was in agreement with the leaf area calculated from the plant samples (Fig. 7). Instead, the leaf area determined with an optical technique (Table 2) constantly produced the lowest values of the observed ones.

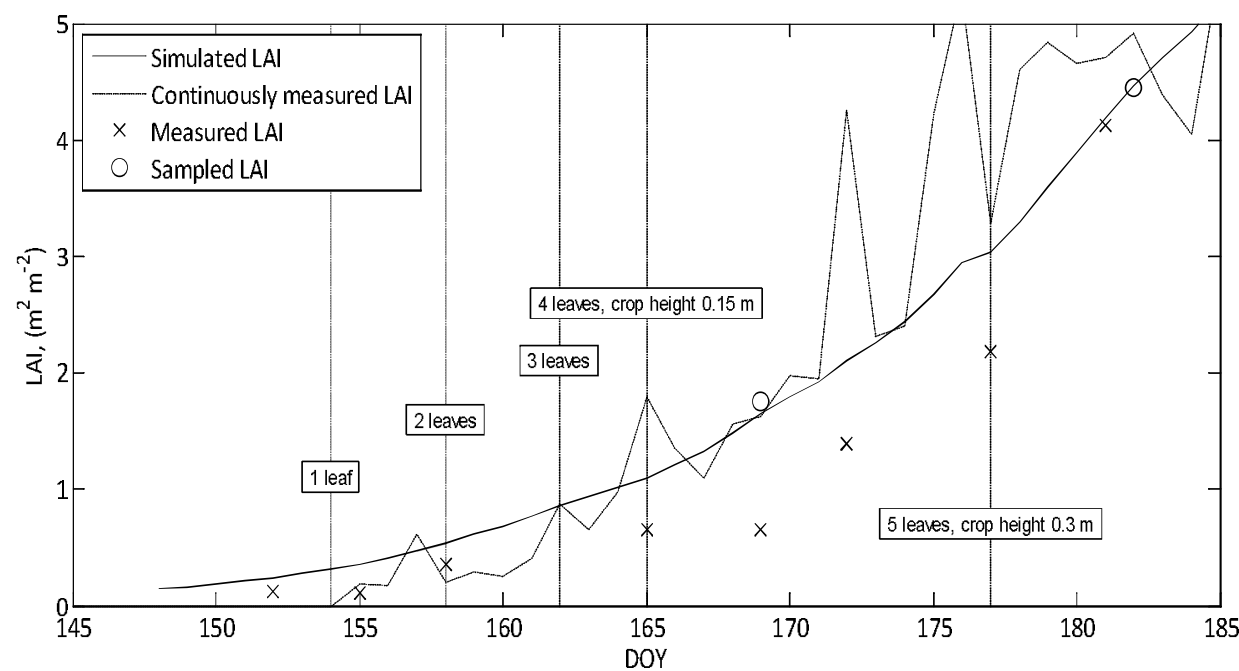

Fig. 7. Simulated and observed crop leaf area accumulation in the natural precipitation treatment in the zone of $50 \mathrm{~kg} \mathrm{~N} \mathrm{ha} \mathrm{H}^{-1}$ fertilization. The measured values are from measurements with the optical device (Decagon LP-80) whereas calculated values present the leaf area calculated from plant samples. The continuous LAI measurement values were determined from the two installed Decagon QSO-S sensors (Table 2).

The leaf area accumulation rate was the highest in the natural precipitation treatment in both simulations and observations due to the highest incoming PAR (data not shown). Since leaf area was measured throughout the season with an optical technique that constantly produced the lowest values, the RM SE value for LAI was not calculated.

The difficulties of the two-radiation-sensor based LAI measurements can be seen in Figure 7 as rapidly fluctuating values (dotted line). However, for practical applications these variations can be filtered out e.g. by averaging the data from on-the-go measurement over a period long enough (in order to get a representative measurement of the canopy). The result of a single measurement is highly dependent on the sensing area size of measurement device, leaf distribution in the canopy and radiation intensity at the time of measurement. A small sensing area together with low canopy leaf area produces varying results since the small sensing head is occasionally covered by a leaf. Further on this will lead to highly varying radiation values below the canopy (Fig. 8). In Figure 8 the continuous radiation measurement results are shown from three adjacent days. The grey area highlights the time interval that was used in the LAI calculation. During the $161^{\text {st }}$ DOY the presence of small leaves can be seen as high and low radiation values below the canopy. The variation in solar radiation intensity was demonstrated on $159^{\text {th }}$ and $160^{\text {th }}$ DOY's where the sun was shaded at the beginning of the day and unevenly during a cloudy day, respectively. 


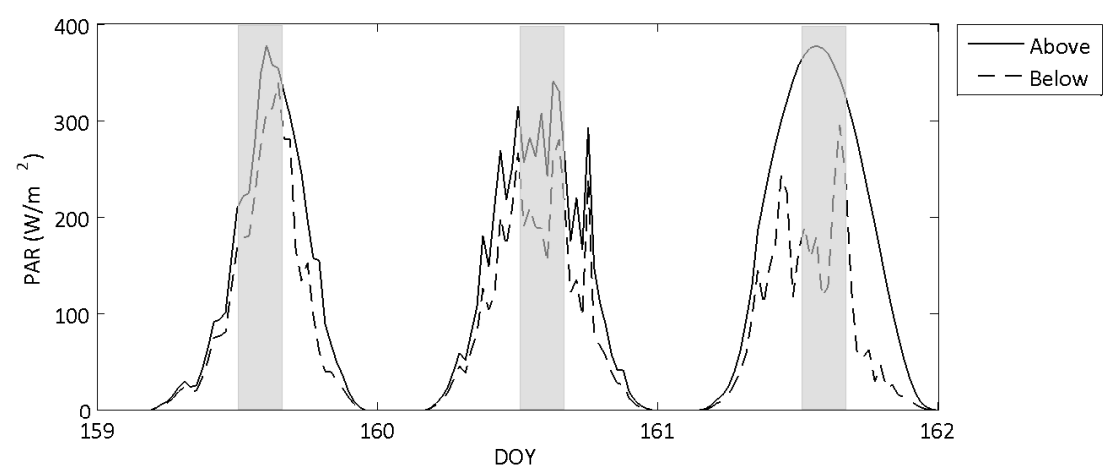

Fig. 8. Solar PAR intensity measured from above the canopy and below the canopy. The grey areas highlight the time interval which was used in the LAl calculation from the radiation measurements (Fig. 7). Results are from the zone of natural precipitation with $\mathrm{N}$ fertilization $50 \mathrm{~kg} \mathrm{ha}^{-1}$ (Fig. 1). The LAl values calculated from measured PAR from left to right were $0.4,0.6$ and 0.8 , respectively.

\section{Discussion \\ Moisture conditions during the experiment}

The objective of the study was to test the model in growing conditions where water is not lacking and limiting growth. Even though the precipitation during examined growing season was low, soil moisture conditions were found to be sufficient for optimal crop growth according to the measurements in three different ways. According to the soil water content as well as ground water level measurements there was enough water for crop growth (Fig. 5A). Soil water potential measurements (Fig. 5B) also justified this statement by revealing that the soil water potential in the deepest measured depth had decreased relatively late and the roots had grown even deeper. In addition, the deepest roots were always found to lay in the moist soil during the crop root measurements.

In previous studies, high canopy temperature compared to surrounding air temperature has been found to indicate low transpiration rate of canopy caused by a low rate of photosynthesis due to water shortage (Ehrler et al. 1978, Blum et al. 1982, Huband and M onteith 1986, Tilling et al. 2007, Cohen et al. 2011). In our experiment the canopy temperature was measured via thermal radiation. During the vegetative growth phase the canopy temperature was found constantly several degrees lower than the air temperature (Fig. 4). Based on the temperature difference the crop was concluded to transpire without interruptions and the water availability for the crop to be sufficient. Since water availability was not limiting growth, the conditions in the highest fertilization and normal precipitation zone were concluded to be as optimal as can be in prevailing radiation conditions.

\section{The experiment and the simulation results}

The highest fertilization treatment produced the highest yield in all radiation treatments (Table 3). The amount of nitrogen has been found to affect the chlorophyll content and the photosynthesis rate of the leaves (Peltonen et al. 1995, Shanahan et al. 2008). At the natural precipitation zone the fertilizer treatment with $50 \mathrm{~kg} \mathrm{~N} \mathrm{ha}^{-1}$ was very close to simulated optimal biomass accumulation and could not be distinguished from the highest fertilizer treatment (Table 3). The crop in the $150 \mathrm{~kg} \mathrm{~N}^{-1}$ treatment had possibly reached the plateau (about $120 \mathrm{~kg} \mathrm{~N}$ $\mathrm{ha}^{-1}$ for spring wheat, Peltonen et al. 1995) above which growth cannot be notably increased by adding nutrients. Therefore the optimal amount of fertilization has probably been between 50 and $150 \mathrm{~kg} \mathrm{ha}^{-1}$ and the growth in the highest fertilization treatment was concluded to be not limited by nutrients. The highest fertilization treatment with natural precipitation produced the highest biomass yield in the experiment (Table 3). This combination of treatments was also in the closest agreement with the simulated biomass accumulation (Table 4).

The total biomass yield below the shelter (zero and double precipitation treatments) was decreased due to the decreased PAR. The biomass yield decrease was in agreement with the shelter PAR absorbance in the observed and in the simulated biomass yields. The observed total biomass yields below the shelter from the zero and double precipitation treatments were the same in all fertilization treatments (Table 3). The effect of precipitation treatments was lower than the effect of fertilization rates. The discrepancy between simulated and observed biomass accumulations was larger due to nutrient limited crop growth (Table 4). 
The total observed biomass yield below the shelter was higher than simulated. Based on observations (soil water potential, canopy temperature, the depth of the roots and ground water level) the reason was concluded to be the high water table level that has provided additional water for the crop in the zero precipitation treatment (data not shown). Because the effect of high water table level was not included in the model, the simulated biomass accumulation indicated a slight lack of water at the end of the growth in the zero precipitation treatment. The crop available water in the model is the difference between FC and PWP that is probably one of the simplest ways to perform the calculation but at the same time does restrict the model usability e.g. for soils with a strong capillary rise. Including features such as water table depth or water movement according to the Darcy's law could improve the model's performance and applicability. However, the structure of the model would become more complex and it would need more parameters that again would be disadvantageous for practical applications of the model as the availability of site-specific parameter values has been shown to be problematic (Sadler et al. 2000, Batchelor et al. 2002).

\section{Model, the parameters and the values for parameters}

The model used in this study has a low number of parameters and the parameters have constant values over the simulated time period. In this study the constant parameter values were used for LWR and root growth but this is not mandatory. Instead of constant values, measurement results or a function describing the development of the parameter could be used as well. Crop characteristics like the biomass allocation (e.g. Kleemola et al. 1996, Kleemola et al. 1998) or root growth (e.g. Pietola and Alakukku 2005) are known to change during the growing season. However, over a limited time period such features of a crop can be assumed to be constant and therefore constant parameters can be used. For instance, in a previous study, the amount of roots for barley and oats was found to steadily increase around the first two months that covers the most of the vegetative growth (Pietola and Alakukku 2005). Some of the crop models (e.g. SUCROS and WOFOST) use equations based on phenological development (heat summation) for considering the changes in the biomass allocation during the growth (e.g. Diepen et al. 1989, Bouman et al. 1996, Van Ittersum et al. 2003). However, the crop biomass allocation is an optimization problem where photosynthesis and growth are maximized, which means balancing between growing roots and/or leaves (e.g. Charles-Edwards 1976, Xinyou and van Laar 2005). Therefore more dynamic approaches for biomass allocation to roots have been suggested (e.g. Kleemola et al. 1996, Kleemola et al. 1998) to consider the changes in crop structure due to the varying growing conditions. Still, simple approaches have been widely used in crop models due to limited information on the roots (Wang and Smith 2004).

In this study, values for the parameters were obtained through measurements. If values from previous study (Hautala and Hakojärvi 2011), for instance, would have been used, the RM SE values would have varied between 440-1980 kg ha-1 for biomass. The parameter values from the previous study would have led to higher simulated biomass accumulation but could serve as initial guess for parameter values if measured information did not exist. A model parameter sensitivity analysis showed that the model parameters RUE, LWR and SLA had the highest effect on the biomass accumulation (Hautala and Hakojärvi 2011). A value for RUE can be assumed to be constant over the growing seasons as long as there are no changes in the crop photosynthesis system. The values for LWR and SLA are perhaps more vulnerable for changes due to the growing conditions but major changes can be assumed to only occur in most extreme conditions. More results on SLA and biomass allocation measurements in varying conditions would be needed to confirm this assumption. Because measuring these parameters is tedious, the values from this or the preceding or study (Hautala and Hakojärvi 2011) could be used during normal growing seasons. However, due to the reasons mentioned above, measured values should be preferred.

Acquiring the parameter values at farm level may be a tedious task but different kinds of solutions for on-the-go measurements or measuring continuously some of the important quantities may provide attractive options for such challenges. The crop itself can be measured directly by means of leaf area, light reflectance in field (Scmidhalter et al. 2008) or indirectly by means of soil water (Tiusanen 2009) or nutrient content (Schmidhalter et al. 2008) in the soil. When information from large areas is needed, the soil surface or crop canopy can be measured directly by remote sensing (Shanahan et al. 2008, Laurila et al. 2010, Hu and Mo 2012) before the field is actually entered with a machine.

In case of soil moisture the measurement may be a competitive alternative for modelling since extensive spatial information about soil properties (especially water related properties) is rarely available on farms and such information is either tedious or expensive to acquire. The soil moisture can be measured from large areas with Soil Scouts that are entirely embedded in soil and send information about soil moisture status wirelessly (Tiusanen 2009). However, there are also challenges in the measurements. The volumetric water content was measured during the experiment and the results from $0.2 \mathrm{~m}$ depth were contrastingly low in comparison to the other depths 
(Fig. 5A). The same exception was not found in the soil water potential measurements (Fig. 5B). The reasons for exceptionally low values in the single measured depth are probably due to small volume of soil measured by the sensor and a possible large pore in the measured volume of soil. This is a challenge that can't be avoided with careful installation because the soil at the sensor location cannot be inspected without destroying the structure. However, the challenge can be addressed with a sensor that measures larger volume of soil.

\section{Applying the model and future remarks}

M easuring crop growth during an actual growing season (Girma et al. 2007, Shanahan et al. 2008) and using the crop growth model together are essential for timing and sizing the amount of additional fertilizer, as suggested in earlier studies (e.g. Welsh et al. 2003a, b, Wood et al. 2003). Canopy measurements tell the crop's momentary state at the time of measurement, e.g. leaf chlorophyll content is measured to estimate the nitrogen status of the crop (Peltonen et al. 1995, Grindlay 1997, Shanahan et al. 2008) but is not alone sufficient for sizing an additional fertilizer dosage. The comparison between measured biomass and simulated (optimal) biomass accumulation is needed to solve if the growth has been optimal or diminished (Hakojärvi and Hautala 2010). Dosage of an additional fertilizer application can be based on the difference between the simulated and measured biomasses. If the measured growth is less than the simulated, the growth has not been optimal for some reason and therefore the site needs less additional fertilization for the remaining growth than would have been needed for optimal growth.

The model does not reveal the growth limiting factor, but gives instead information if such a factor should be searched for or not. In a case similar to our experiment, comparison between the simulated and observed biomass accumulation would have shown that the growth has been restricted in all treatments excluding the one with natural precipitation and highest fertilization. Deeper investigation would have shown that the growth limiting factors were decreased radiation and nutrient availability. Finally, fertilizer application after these investigations could have been adjusted respectively; remembering that a yield loss that has already occurred cannot be revoked. The model alone cannot provide a final solution for the problem of enhancing the use of farming inputs but it is an important part of a possible solution.

Using the model doesn't remove the challenges related to the fertilizer application during the growing season when the nutrients from broadcast of a granular fertilizer are not available for the crop until the water has moved the nutrients to the roots (Peltonen 1995, Petersen 2004) and only small amounts of nutrients can be applied as a foliar spray in one treatment according to the instruction of currently sold products.

The timing of fertilizer application is another challenge but can be based on the previous application (timing and rate) and a few well-known fertilization timing effects. In the beginning of the growth, a low level of available nitrogen may decrease the number of grains in a single ear of a small grain cereal (Jenner et al. 1991, Peltonen 1995). A high amount of available nitrogen during the vegetative growth increases the grain size (Kraybill 1932, Finney et al. 1957, Parameswaran et al. 1981, Spiertz and De Vos 1983, Jenner et al. 1991, Peltonen 1995). If higher protein concentration is an important factor of wheat yield, then the availability of nitrogen is important after the anthesis (Peltonen 1995). In addition to these indicative application timing guidelines it may be relevant to also consider changes in crop development rate when high fertilization rates are used.

In conclusion, crop growth in our experiment was not limited by water availability based on the soil measurements and crop observations during the experiment. Therefore the crop biomass accumulation in the highest fertilization treatment was concluded to be as high as possible in prevailing temperature and radiation conditions. The simulated biomass accumulation was in closest agreement to the experiment results from the highest fertilization treatment according to the RM SE values (Table 4). The simulated biomass accumulation in the reduced PAR treatment was in agreement with the observed experiment result. The simulated leaf area was in agreement with the observed leaf area calculated from the plant samples as well as with the radiation based measurement results (Fig. 7). The radiation measurement was found to offer a practical way over the tedious sampling to determine the prevailing biomass during fertilization. When LAl is known the biomass can be calculated using the formula in Equation 3. The information about current growth as well as the knowledge of potential biomass accumulation given by the model at the time of application are needed for fertilization adjustment. The model successfully simulated the potential biomass accumulation during the early growth of the crop when measured model parameters were used. It is to be stressed out that the model does not have any free parameters without a solid basis. Therefore the model was concluded to be suitable for calculation of potential biomass accumulation at the vegetative growth phase, which is the time period when additional fertilizer must be applied to have an effect on the crop growth. 


\section{Acknowledgements}

We thank M uhis Sepahi for the skilled work both in the field and in the laboratory. Pirjo Mäkelä, Fred Stoddard and Johannes Tiusanen are gratefully thanked for critical comments of the manuscript. We thank two anonymous reviewers for their pertinent and constructive comments on our manuscript. We gratefully acknowledge the financial support provided by Maatalouskoneiden tutkimussäätiö for this study.

\section{References}

Adams, M.L., Cook, S. \& Corner, R. 2000. Managing Uncertainty in Site-Specific M anagement: What is the Best M odel? Precision Agriculture 2: 39-54.

Angus, J.F. \& Fisher, R.A. 1991. Grain and Protein Responses to Nitrogen Applied to Wheat Growing on a Red Earth. Australian Journal of Agricultural Research 42: 735-746.

Asseng, S., Turner, N.C. \& Keating, B.A. 2001. Analysis of water- and nitrogen-use efficiency of wheat in a M editerranean climate. Plant and Soil 233: 127-143.

Barberi, P.A., Rozas, H.S. \& Echeverría, H.E. 2008. Time of nitrogen application affects nitrogen use efficiency of wheat in the humid pampas of Argentina. Canadian Journal of Plant Science 88: 849-857.

Basso, B., Cammarano, D., Fiorentino, C. \& Ritchie, J.T. 2013. Wheat yield response to spatially variable nitrogen fertilizer in M editerranean environment. European journal of Agronomy 51: 65-70.

Basso, B., Fiorentino, C. Cammarano, D., Cafiero, G. \& Dardanelli, J. 2012. Analysis of rainfall distribution on spatial and temporal patterns of wheat yield in M editerranean environment. European Journal of Agronomy 41:52-65.

Basso, B., Ritchie, J.T., Cammarano, D. \& Sartori, L. 2011. A strategic and tactical management approach to select optimal N fertilizer rates for wheat in a spatially variable field. European Journal of Agronomy 35: 215-222.

Basso, B., Cammarano, D., Chen, D., Cafiero, G., Amato, M., Bitella, G., Rossi, R. \& Basso, F. 2009. Landscape Position and Precipitation Effects on Spatial Variability of Wheat Yield and Grain Protein in Southern Italy. Journal of Agronomy \& Crop Science 195: $301-312$.

Basso, B., Ritchie, J.T., Pierce, F.J., Braga, R.P. \& Jones, J.W. 2001. Spatial validation of crop models for precision agriculture. Agricultural Systems 68: 97-112.

Batchelor, W.D., Basso, B. \& Paz, J.O. 2002. Examples of strategies to analyze spatial and temporal yield variability using crop models. European Journal of Agronomy 18: 141-158.

Blackmore, S., Godwin, R.J. \& Fountas, S. 2003. The Analysis of Spatial and Temporal Trends in Yield Map Data over Six Years. Biosystems Engineering 84: 455-466.

Blum, A., M ayer, J. \& Gozlan, G. 1982. Infrared thermal sensing of plant canopies as a screening technique for dehydration avoidance in wheat. Field Crops Research 5: 137-146.

Boote, K.J., Jones, J.W. \& Pickering, N.B. 1996. Potential uses and limitations of crop models. Agronomy Journal 88: 704-716.

Bouman, B.A.M., Van Keulen, H., Van Laar, H.H., \& Rabbinge, R. 1996. The 'School of de Wit'crop growth simulation models: a pedigree and historical overview. Agricultural Systems 52: 171-198.

Brooks, R.J., Semenov, M.A. \& Jamieson, P.D. 2001. Simplifying sirius: Sensitivity analysis and development of a meta-model for wheat yield prediction. European Journal of Agronomy 14: 43-60.

Calex Electronics Limited 2005. Convir EL Series Low Cost Non-Contact Temperature Sensor. Cited 8 July 2011. Updated 16 June 2014. Available on the Internet: http://www.omniinstruments.co.uk/products/product/moredetails/convir.id139.html.

Charles-Edwards, D.A. 1976. Shoot and root activities during steady-state plant growth. Annals of Botany 40: 767-772.

Cohen, Y., Alchanatis, V., Prigojin, A., Levi, A. \& Soroker, V. 2011. Use of aerial thermal imaging to estimate water status of palm trees. Precision Agriculture 13: 123-140.

Decagon Devices Inc. 2009a. M PS-1 Dielectric Water Potential Sensor Operator's Manual Version 3.0, 2350 NE Hopkins Court, Pullman, WA 99163.

Decagon Devices Inc. 2009b. PAR Photon Flux Sensor M odel QSO-S, 2365 NE Hopkins Ct, Pullman, WA 99163.

Decagon Devices Inc. 2010. AccuPAR PAR/LAl ceptometer model LP-80 Operator's Manual, Version 10, Decagon Devices, Inc., 2365 NE Hopkins Court, Pullman, WA 99163.

Diacono, M., Castrignanò, A., Troccoli, A., De Benedetto, D., Basso, B. \& Rubino, P. 2012. Spatial and temporal variability of wheat grain yield and quality in a M editerranean environment: A multivariate geostatistical approach. Field Crops Research 131: 49-62.

Diepen, C.V., Wolf, J., Keulen, H.V., \& Rappoldt, C. 1989. WOFOST: a simulation model of crop production. Soil use and management 5: 16-24.

Drebs, A., Nordlund, A., Karlsson, P., Helminen, J. \& Rissanen, P. 2002. Climatological Statistics of Finland 1971-2000. Helsinki: Finnish Meteorological Institute.

Ehrler, W.L., Idso, S.B., Jackson, R.D. \& Reginato, R.J. 1978. Wheat canopy temperature: relation to plant water potential. Agronomy Journal 70: 251-256.

Esala, M. 1991. Split application of nitrogen: effects on the protein in spring wheat and fate of $15 \mathrm{~N}$-labelled nitrogen in the soilplant system. Annales Agriculturae Fenniae 30: 219-309. 
Finney, K.F., Meyer, J.W., Smith, F.W. \& Fryer, H.C. 1957. Effect of foliar spraying of Pawnee wheat with urea solutions on yield, protein content, and protein quality. Agronomy J ournal 49: 341-347.

Finnish Meteorological Institute 2010. IImastokatsaus No. 4-9/2010. (In Finnish).

Fitzgerald, G.J., Rodriguez, D., Christensen, L.K., Belford, R., Sadras, V.O. \& Clarke, T.R. 2006. Spectral and thermal sensing for nitrogen and water status in rainfed and irrigated wheat environments. Precision Agriculture 7: 233-248.

Fridgen, J.J., Kitchen, N.R., Sudduth, K.A., Drummond, S.T., Wiebold, W.J. \& Fraisse, C.W. 2004. Management Zone Analyst (M ZA): Software for Subfield M anagement Zone Delineation. Agronomy J ournal 96: 100-108.

Fleming, K.L., Westfall, D.G., Wiens. D.W. \& Brodahl, M.C. 2000. Evaluating Farmer Defined Management Zone Maps for Variable Rate Fertilizer Application. Precision Agriculture 2: 201-215.

Girma, K., Freeman, K.W., Teal, R.K., Arnall, D.B., Tubana, B., Holtz, S. \& Raun, W.R. 2007. Analysis of yield variability in winter wheat due to temporal variability, and nitrogen and phosphorus fertilization. Archives of Agronomy and Soil Science 53: 435-442.

Godwin, R.J., Wood, G.A., Taylor, J.C., Knight, S.M . \& Welsh, J.P. 2003. Precision Farming of Cereal Crops: a Review of a Six Year Experiment to develop Management Guidelines. Biosystems Engineering 84(4): 375-391.

Grindlay, D.J.C. 1997. Towards an explanation of crop nitrogen demand based on the optimization of leaf nitrogen per unit leaf area. Journal of Agricultural Science 128: 377-396.

Hakojärvi, M., Hautala, M., 2010. A new crop growth model: Decision aid for timing and spacing of inputs in precision farming. In: Proceedings of the International Conference on Agricultural Engineering. Clermont-Ferrand, France. REF312. 9 p.

Hakojärvi, M., Hautala, M., Ristolainen, A. \& Alakukku, L. 2013. Yield variation of spring cereals in relation to selected soil physical properties on three clay soil fields. European Journal of Agronomy 49: 1-11.

Hanna, A.Y., Harlan, P.W. \& Lewis, D.T. 1982. Soil Available Water as Influenced by Landscape Position and Aspect. Agronomy Journal 74: 999-1004.

Hancock, J.M., McNeill, A.M., M cDonald, G.K. \& Holloway, R.E. 2011. Fate of fertiliser N applied to wheat on a coarse textured highly calcareous soil under simulated semi-arid conditions. Plant Soil 348: 139-153.

Hautala, M . \& Hakojärvi, M. 2011. An analytical C3-crop growth model for precision farming. Precision Agriculture 12: $266-279$. Havling, J.L. \& Heininger, R.W. 2009. A variable-rate decision support tool. Precision Agriculture 10: 356-369.

Honeywell International Inc. 2005. HIH-4000 Series Humidity Sensors. Cited 8 July 2011. Updated 16 June 2014. Available on the Internet: http://sensing.honeywell.com/product\%20page?pr_id $=53944$.

Hu, S. \& Mo, X. 2012. Prediction of crop productivity and evapotranspiration with two photosynthetic parameter regionalization methods. Journal of Agricultural Science 152: 119-133.

Huband, N.D.S. \& Monteith, J.L. 1986. Radiative surface temperature and energy balance of a wheat canopy. Boundary Layer Meteorology 36: 1-17.

Hyytiäinen, K., Niemi, J.K., Koikkalainen, K., Palosuo, T. \& Salo, T. 2011. Adaptive optimization of crop production and nitrogen leaching abatement under yield uncertainty. Agricultural Systems 104: 634-644.

ICT International 2011. M P406 Soil M oisture Probe.Cited 8 July 2011. Updated 16 June 2014. Available on the Internet: http:// www.ictinternational.com/products/mp406/mp406-moisture-sensor/.

James, I.T. \& Godwin, R.J. 2003. Soil, Water and Yield Relationships in developing Strategies for the Precision Application of Nitrogen Fertiliser to Winter Barley. Biosystems Engineering 84: 467-480.

Jenner, C.F., Ugalde, T.D. \& Aspinall, D. 1991. The physiology of starch and protein deposition in the endosperm of wheat. Australian Journal of Plant Physiology 18: 211-226.

J ohnson, G.V. \& Raun, W.R. 2003. Nitrogen response index as a guide to fertilizer management. Journal of Plant Nutrition 26: 249-262.

Jørgensen, J.R. \& Jørgensen, R.N. 2007. Uniformity of wheat yield and quality using sensor assisted application of nitrogen. Precision Agriculture 8: 63-73.

Keller, T., Sutter, J.A., Nissen, K. \& Rydberg, T. 2012. Using field measurement of saturated soil hydraulic conductivity to detect low-yielding zones in three Swedish fields. Soil \& Tillage Research 124: 68-77.

Kleemola, J., Teittinen, M., \& Karvonen, T. 1996. Modelling crop growth and biomass partitioning to shoots and roots in relation to nitrogen and water availability, using a maximization principle. Plant and soil 185: 99-111.

Kleemola, J., Teittinen, M., \& Karvonen, T. 1998. Modelling crop growth and biomass partitioning to shoots and roots in relation to nitrogen and water availability, using a maximization principle. II. Simulation of crop nitrogen balance. European Journal of Agronomy 8: 191-204.

Kraybill, H.R. 1932. Effect of plant nutrition on the composition of wheat. Cereal Chemistry 9: 71-82.

Kuisma, P. 2002. Efficiency of split nitrogen fertilization with adjusted irrigation on potato. Agricultural and Food Science 11: 59-74.

Lark, R.M. 2001. Some tools for parsimonious modelling and interpretation of within-field variation of soil and crop systems. Soil \& Tillage Research 58: 99-111.

Laurila, H., Karjalainen, M., Hyyppä, J. \& Kleemola, J. 2010. Integrating Vegetation Indices M odels and Phenological Classification with Composite SAR and Optical Data for Cereal Yield Estimation in Finland (Part I). Remote Sensing 2: 76-114.

M okma, D. L., Yli-Halla, M \& \& Hartikainen, H. 2000. Soils in a young landscape on the coast of southern Finland. Agricultural and Food Science 9: 291-302. 
M onteith, J.L. \& M oss, C.J. 1977. Climate and the efficiency of crop production in Britain [and discussion]. Philosophical Transactions of the Royal Society of London. Series B, Biological Sciences 281: 277-294.

M orison, J.I.L., Baker, N.R., M ullineaux, P.M . \& Davies, W.J. 2008. Improving water use in crop production. Philosophical Transactions of the Royal Society B: Biological Sciences 363: 639-658.

Mulla, D.J., Bhatti, A.U., Hammond, M.W., \& Benson, J.A. 1992. A comparison of winter wheat yield and quality under uniform versus spatially variable fertilizer management. Agriculture, ecosystems \& environment 38: 301-311.

Olesen, J.E., M ortensen, J.V., Jørgensen, L.N. \& Andersen, M .N. 2000. Irrigation strategy, nitrogen application and fungicide control in winter wheat on a sandy soil. I. Yield, yield components and nitrogen uptake. Journal of Agricultural Science, Cambridge 134: 1-11. Parameswaran, K.V.M., Graham, R.D. \& Aspinal, D. 1981. Studies on the Nitrogen and Water Relations of Wheat. Irrigation Science 3: 29-44

Peltonen, J., Virtanen, A. \& Haggrèn, E. 1995. Using a Chlorophyll M eter to Optimize Nitrogen Fertilizer Application for Intensively-M anaged Small-Grain Cereals. Journal of Agronomy \& Crop Sciences 174: 309-318.

Pedersen, L., \& Jørgensen, J.R. 2007. Variation in rheological properties of gluten from three biscuit wheat cultivars in relation to nitrogen fertilisation. Journal of cereal science 46: 132-138.

Petersen, J. 2004. Crop uptake of ${ }^{15} \mathrm{~N}$ labelled fertilizer in spring wheat affected by application time. Acta Agriculturae Scandinavica, Section B-Soil \& Plant Science 54: 83-90.

Pierce, F.J. \& Nowak, P. 1999. Aspects of Precision Agriculture. Advances in Agronomy 67: 1-85.

Pietola, L. \& Alakukku, L. 2005. Root growth dynamics and biomass input by Nordic annual field crops. Agriculture, ecosystems $\&$ environment 108: 135-144.

Poorter, H. \& Nagel, O. 2000. The role of biomass allocation in the growth response of plants to different levels of light, $\mathrm{CO}_{2}$, nutrients and water: A quantitative review. Functional Plant Biology 27: 595-607.

Rankinen, K., Peltonen-Sainio, P., Granlund, K., Ojanen, H., Laapas, M., Hakala, K., Sippel, K., Helenius, J. \& Forsius, M. 2013. Climate change adaptation in arable land use, and impact on nitrogen load at catchment scale in northern agriculture. Agricultural and Food Science 22: 342-355.

Sadler, E.J., Gerwig, B.K., Evans, D.E., Busscher, W.J. \& Bauer, P.J. 2000. Site-specific modeling of corn yield in the SE coastal plain. Agricultural Systems 64: 189-207.

Sadras, V.O., Lawson, C., Hooper, P. \& M CDonald, G.K. 2012. Contribution of summer rainfall and nitrogen to the yield and water use efficiency of wheat in M editerranean-type environments of South Australia. European Journal of Agronomy 36: 41-54.

Schmidhalter, U., M aidl, F. -X., Heuwinkel, H., Demmel, M., Auernhammer, H., Noack, P. \& Rothmund, M. 2008. Precision farming - adaptation of land use management to small scale heterogeneity. In: Schröder, P., Pfadenhauer, J. \& M unch, J.C. (eds.). Perspectives for Agroecosystem M anagement. Amsterdam:Elsevier. p. 121-199.

Shanahan, J. F., Kitchen, N. R., Raun, W. R. \& Schepers, J. S. 2008. Responsive in-season nitrogen management for cereals. Computers and electronics in agriculture 61: 51-62.

Sinclair, T.R. \& Seligman, N.G. 1996. Crop modeling: From infancy to maturity. Agronomy Journal 88: 698- 704.

Singh, A.K., Tripathy, R. \& Chopra, U.K. 2008. Evaluation of CERES-Wheat and CropSyst models for water- nitrogen interactions in wheat crop. Agricultural water management 95: 776-786.

Soil M oisture Equipment Corp. 2011. TDR M iniTRASE Kit. Cited 8 July 2011. Updated 16 June 2014. Available on the Internet: http://www.ictinternational.com/ products/6050x3k5b/minitrase-kit/.

Spiertz, J.H.J. \& De Vos, N.M. 1983. Agronomical and physiological aspects of the role of nitrogen in yield formation in cereals. Plant and Soil 75: 379-391.

Taylor, J.C., Wood, G.A., Earl, R. \& Godwin, R.J. 2003. Soil factors and their influence on within-field crop variability, Part II: spatial analysis and determination of management zones. Biosystems Engineering 84: 441-453.

Tike 2011. Yearbook of farm statistics 2011. Helsinki, Finland: Information Centre of the Ministry of Agriculture and Forestry.

Tilling, A.K., O'Leary, G.J., Ferwerda, J.G., Jones, S.D., Fitzgerald, G.J. \& Rodriguez, D. 2007. Remote sensing of nitrogen and water stress in wheat. Field Crops Research 104: 77-85.

Timlin, D., Pachepsky, Y., Walthall, C. \& Loechel, S., 2001. The use of a water budget model and yield maps to characterize water availability in a landscape. Soil \& Tillage Research 58: 219-231.

Tinytag 2011. Tinytag Ultra 2 Temperature/ Relative Humidity Logger Datasheet, Issue 9, 21st April 2011.

Tiusanen, J. 2009. Wireless soil scout prototype radio signal reception compared to the attenuation model. Precision Agriculture 10: $372-381$.

Van Ittersum, M.K., Leffelaar, P.A., Van Keulen, H., Kropff, M.J., Bastiaans, L. \& Goudriaan, J. 2003. On approaches and applications of the Wageningen crop models. European Journal of Agronomy 18: 201-234.

Viljavuuspalvelu 2010. Viljavuustutkimus: M enetelmät ja epätarkkuudet.

Walsh, O.S., Klatt, A.R., Solie, J.B., Godsey, C.B. \& Raun, W.R. 2013. Use of soil moisture data for refined GreenSeeker sensor based nitrogen recommendations in winter wheat (Triticum aestivum L.). Precision Agriculture 14: 343-356.

Wang, E., \& Smith, C.J. 2004. Modelling the growth and water uptake function of plant root systems: a review. Crop and Pasture Science 55: 501-523.

Welsh, J.P., Wood, G.A., Godwin, R.J., Taylor, J.C., Earl, R., Blackmore, S. \& Knight, S.M . 2003a. Developing Strategies for Spatially Variable Nitrogen Applications in Cereals, Part I: Winter Barley. Biosystems Engineering 84: 481-494. 
Welsh, J.P., Wood, G.A., Godwin, R. ., Taylor, J.C., Earl, R., Blackmore, S. \& Knight, S.M . 2003b. Developing Strategies for Spatially Variable Nitrogen Applications in Cereals, Part II: Wheat. Biosystems Engineering 84: 495-511.

Wood, G.A., Welsh, J.P., Godwin, R.J., Taylor, J.C., Earl, R. \& Knight, S.M . 2003. Real-time Measures of Canopy Size as a Basis for Spatially Varying Nitrogen Applications to Winter Wheat sown at Different Seed Rates. Biosystems Engineering 84: 513-531.

Xinyou, Y., \& Van Laar, H.H. 2005. Crop systems dynamics: an ecophysiological simulation model for genotype-by-environment interactions. Wageningen: Academic Publishers, The Netherlands. $155 \mathrm{p}$. 